\title{
Zero-a-Seis
}

\section{PERCURSOS E PERCALÇOS DAS PESQUISAS COM CRIANÇAS EM CONTEXTOS DE CHEGADAS E PARTIDAS: REFLEXÕES SOBRE PESQUISAS EM PROGRAMAS DE ACOLHIMENTO INSTITUCIONAL}

Routes and difficulties of research with children in contexts of arrivals and departures: reflections on research in programs institutional care

\author{
Roseli NAZÁRIO \\ PPGE IFC campus Camboriú \\ Instituto Federal Catarinense - Camboriú, Brasil \\ roseli.nazario@ifc.edu.br
}

\author{
Kamila Barros TIZATTO \\ Graduação em Pedagogia \\ Instituto de Ensino Superior Santo Antônio, Joinville, Brasil \\ kamila_tizatto@santoantonio.edu.br
}

A lista completa com informações dos autores está no final do artigo

\section{RESUMO}

Este artigo compartilha uma reflexão articulada a partir da análise de duas pesquisas realizadas com crianças em programas de acolhimento institucional instalados em Santa Catarina. A partir dele objetivouse lançar luz sobre os processos teórico-metodológicos adotados por essas pesquisas, de modo a colocar em relevo dois pontos que se interseccionam: i) as implicações postas para a entrada no campo, sob a forte tensão entre o direito de proteção e o direito de participação das crianças; ii) a emergência por desenvolver estratégias comunicativas que envolvam as crianças nas pesquisas, construídas sobre as próprias habilidades e capacidades dessas crianças. Sua base teórica se assenta nos Estudos da Infância, ao afirmar a infância como categoria geracional e as crianças como atores sociais plurais nos seus modos de agência.

PALAVRAS-CHAVE: Acolhimento institucional; Pesquisa com crianças; Ética na pesquisa com crianças.

\begin{abstract}
This article shared an articulated analysis based on two researches with children in institutional care programs implemented in Santa Catarina. The objective was to shed light on the theoretical-methodological processes adopted by which research, in order to place in a point of view, intersect: i) the posts put in for entry into the field, under a strong tension between the right of protection and the right of children to participate; $\mathrm{ii}$ ) emergence through communicative actions involving children in research, built on how they are capable and the children. Its theoretical basis is based on the Studies of Childhood, at the same time as it refers to the generation and how children as plural social actors in their modes of action.
\end{abstract}

KEYWORDS: Institutional care; Research with children; Ethics in research with children.

\section{PALAVRAS INICIAIS}


A trajetória histórica dos Estudos da Infância "tem sido marcada não por uma ausência de interesse pelas crianças, mas pelo seu silêncio" (FERREIRA, 2010, p. 154), embora seja possível observar o crescente volume de pesquisas interessadas em escutar 1 as experiências e pontos de vista das crianças. Tal fato indica a emergência de um novo paradigma para os estudos da infância, o que reflete, em parte, um afastamento da visão das crianças como recipientes passivos da socialização adulta (O'KANE, 2005), de modo a emergir o reconhecimento de que elas são atores sociais de direito próprio e com efetiva participação na construção e determinação das suas experiências e das sociedades onde vivem.

Ao considerar que a história da infância é, sobretudo, uma história de representações, por conta das raras evidências nas quais poderia se fundamentar uma história própria das crianças (BUCKINGHAM, 2007), não são poucas as incertezas que estamos enfrentando no início deste século XXI, quando escrevemos sobre elas e sobre a infância. Dito de outra forma, no nosso processo de constituição social não foi outorgado à criança o direito de escrever sua própria história e, deste modo, não podemos deixar de considerar que "a história da criança é uma história sobre a criança" (KUHLMANN Jr, 1998, p. 31).

A crítica a essa trajetória histórica que não pensou a infância e nem as crianças a partir delas próprias, mas sim, sempre as pensou partindo de outros quadros de referência - as crianças na família, na escola - tem contribuído para a produção de conhecimentos sobre quem são as crianças reais, quais suas formas de agrupamento e suas culturas (PINTO e SARMENTO, 1997; SARMENTO, 2003; 2005; 2013; DELGADO e MULLER, 2008; entre outros).

Deste modo e atendendo aos indicativos de Kuhlmann Jr. (1998, p.31):

É preciso considerar a infância como uma condição da criança. O conjunto de experiências vividas por elas em diferentes lugares históricos, geográficos e sociais é muito mais do que uma representação dos adultos sobre esta fase da vida. É preciso conhecer as representações da infância e considerar as crianças concretas, localizá-las nas relações sociais, etc, reconhecê-las como produtoras de história.

1 Para ampliação do sentido, essa escuta deve ser tomada na dimensão da auscultação, a qual, segundo Rocha (2010, p. 19) "redefine nossa ação, não como uma mera percepção auditiva ou recepção da informação - envolve a compreensão da comunicação feita pelo outro. Inclui a recepção e a compreensão, que, principalmente neste caso - a expressão do outro/criança orienta-se pelas próprias intenções colocadas nessa relação comunicativa - e lembremos que, quando o outro é uma criança, a linguagem oral não é central e nem única, ela é fortemente acompanhada de outras expressões corporais, gestuais e faciais". 
Neste sentido, concentra-se nos primeiros anos deste século XXI uma crescente produção de estudos nacionais e internacionais em diferentes campos do conhecimento alicerçada na afirmação da infância como categoria histórica e social, produções essas que compartilham a preocupação em torno de fazer pesquisa com crianças2, concebidas como "sujeitos do conhecimento, sujeitos sociais situados na história, que produzem cultura e são nela produzidos, atores sociais, cidadãos de direito" (KRAMER, 2013, p. 388).

Este campo de ciências críticas não procura estabelecer generalizações sobre a infância, mas sim, a construção de um conhecimento situado local e historicamente sobre a infância e a criança e, através de novas relações disciplinares, criar estabilidades e referências que não representem verdades estanques e absolutas. Em suma, busca construir imagens da infância a partir da descrição, da escuta das vozes e da participação das crianças (BARBOSA; DELGADO; TOMÁS, 2016).

Esse movimento exigiu "compreender o outro diferente de si [...] dialogando com outras formas de conhecimento, tendo por base e pressuposto central o mundo da cultura, as relações entre os homens e a construção do saber" (GUSMÃO, 1997, p. 13), provocando no Brasil a necessidade e o grande interesse da educação por aproximarse de outros campos do conhecimento, em grande medida, da Antropologia da criança e da Sociologia da infância, o que, de certo modo, encorajou assumir a etnografia como a mais recorrente entre as pesquisas, justamente pela "experiência de proximidade", como defende Geertz (1999).

Em uma pesquisa etnográfica com crianças sempre devemos tratá-las como crianças, mas não da forma usual como os adultos as tratam. É nisso que reside o desafio: "vislumbrar a alteridade das infâncias como um conjunto de aspectos que distinguem as crianças dos adultos e reconhecer as culturas da infância como um modo específico de interpretação e representação do mundo", como defendem Delgado e Müller (2008, p. 164-165). Deste modo, vê-se que a alteridade se torna fundamental não somente para o conhecimento do outro, mas também do pesquisador como um

2 Embora aqui não possamos deixar de registrar que uma das primeiras coletâneas voltadas inteiramente às pesquisas sobre e com crianças consiste no "Cadernos de Pesquisa" (No 31), publicado pela Fundação Carlos Chagas, em dezembro de 1979, e que reúne um conjunto de artigos e autores de diferentes campos do conhecimento (Antropologia; Sociologia; Psicologia; Educação; Pediatria, Direito, Arquitetura; Jornalismo), atendendo aos indicativos mais atuais de que a infância é um campo disciplinar de natureza interdisciplinar, como expressa Sônia Kramer (2013). 
outro, assim como da criança como um outro que nos faz rever essa posição de pesquisador e sua alteridade de adulto. (SILVA, BARBOSA, KRAMER, 2005).

Assim, fazer etnografia implica olhar de perto e de dentro (MAGNANI, 2002), construir intimidade (BARROS, 2006) 3 e, no que se refere a especificidade deste texto, a experiência de aproximação se deu a partir de reflexões resultantes de duas pesquisas realizadas em programas de acolhimento institucional, voltados às crianças temporariamente afastadas do convívio familiar e comunitário4.

Ambas são pesquisas vinculadas ao Programa de Pós-Graduação em Educação da Universidade Federal de Santa Catarina (PPGE UFSC) e integram os estudos das linhas de pesquisa "Ensino e Formação de Educadores" e "Educação e Infância", tendo em comum um cerne investigativo que busca compreender como as crianças experienciam suas infâncias no contexto de acolhimento institucional, elegendo-as como as principais informantes na geração dos dados das pesquisas e, para tanto, debruçaram-se criticamente sobre muitos questionamentos, alguns desse citados mais adiante.

A primeira delas trata-se da tese de doutoramento de autoria de Nazário (2014), efetivamente trilhada a partir de um percurso metodológico etnográfico, cujas horas de estada no campo, minutadas em anotações escritas, imagens filmadas e fotografadas, possibilitaram a aproximação às narrativas infantis, tendo como agentes crianças entre zero e seis anos de idade. Neste estudo, a interlocução com diferentes áreas disciplinares contribuiu para a afirmação da infância enquanto categoria geracional e campo de estudo em construção.

A segunda consiste na dissertação de mestrado de Tizatto (2018), delineada como um estudo de caso, cujo processo de construção de dados contou com o período de aproximadamente 170 horas de imersão no campo e lançou mão de diversos recursos comuns à etnografia, como observação participante, diálogo com crianças, registro detalhado das notas de campo em registros escritos e fotografados e a análise sistemática destas informações. Este estudo pôs em evidência as narrativas infantis e como a ação das crianças interroga os processos e estrutura institucionais, culminando

3 Manoel de Barros, o poeta pantaneiro, foi convidado a trilhar este texto e, para demarcar essa presença, suas expressões aparecerão com formatação em itálico.

4 As duas instituições estão situadas no Estado de Santa Catarina, em municípios distintos de grande porte, com dados populacionais que ultrapassam 300 mil habitantes (IBGE, 2018). Uma dessas consiste em uma instituição sob a responsabilidade administrativa do Poder Público Municipal e, a outra, uma organização não-governamental mantida por uma ordem religiosa, contemplada com subvenção do Poder Público. 
na reflexão sobre os contínuos tensionamentos entre o que é proposto institucionalmente e o que é vivido pela criança.

A tessitura dos nossos estudos indicou as crianças como sujeitos que não são passivos e submissos à cultura e códigos instituídos pelos adultos; pelo contrário, subvertem estes saberes hegemônicos através dos seus modos de ser criança e de viver a experiência do acolhimento, ocupando estes espaços tantas vezes definidos por sua provisoriedade, excepcionalidade e descontinuidade, com pessoalidade, afetividade e resistência/existência. A cronologia do tempo instituído como um tempo provisório e, consequentemente, de passagem, do ponto de vista dos adultos, é experienciado pelas crianças por outra temporalidade, de acordo com que lhe é próprio: um tempo recursivo (SARMENTO, 2004), não linear, sem medida. As narrativas das crianças indicam outros sentidos atribuídos a este lugar, dando-Ihe identidade e pertença particular.

Os contextos em que foram realizadas essas pesquisas se constituem em espaços educativos que preservam especificidades em relação aos espaços formais de educação (creche, pré-escola e escola), se considerarmos, entre outros aspectos, a jornada integral de permanência ou, simultaneamente, o duplo processo de institucionalização vivido pelas crianças5, bem como a impermanência que marca tais espaços, frente às chegadas e partidas das crianças, assim como, a rotatividade dos profissionais.

Essas questões, por vezes, geram situação de desassossego, de inquietação e até de angústia, impondo algumas perguntas: como traduzir a necessidade de saber mais sobre a experiência dessa população infantil que frequenta abrigos ou casas lares brasileiras, considerando que neste lugar o acesso às crianças e às informações sobre suas vidas é obstaculizado em nome da proteção? Que percursos trilhar para acessar suas histórias de vida, histórias essas na maioria das vezes invisibilizadas nos protocolos institucionais? O que e como observar, diante deste incessante movimento de entrada e saída de gente pequena e gente grande? Como registrar toda esta dinâmica? Como criar intimidade com sujeitos que habitam um lugar marcado por novos encontros e despedidas constantes? É possível fazer etnografia com crianças neste lugar que se constitui pela provisoriedade, pela transitoriedade?

Assim, se enfrentar o desafio metodológico de observar as crianças em atividades cotidianas em contextos institucionais não é tarefa fácil, levando em conta os aspectos

5 Salvo algumas situações envolvendo crianças de 0 a 3 anos, poucos são os casos em que uma criança ou adolescente não frequente um contexto formal de educação (pré-escola, escola), levando em conta a obrigatoriedade de matrícula na Educação Básica dos 4 aos 17 anos de idade. 
tratados acima, o que dizer, então, dos desafios postos para a entrada no campo? E, é sobre essa questão, em especial, que trataremos na seção seguinte desse texto.

\section{A NEGOCIAÇÃO PARA ENTRADA NO CAMPO: PROTOCOLOS REGULATÓRIOS INSTITUCIONAIS}

Pensando nos aspectos éticos aplicados às pesquisas em contexto de acolhimento institucional, a partir dessa parte do texto passamos a problematizar algumas outras questões, vivenciadas para o ingresso neste campo de pesquisa, uma vez que, se já não é fácil o trabalho de campo, a entrada nesses lugares se torna ainda mais difícil. Isso porque, tal como dito por Graue e Walsh (2003, p. 121-122), "os responsáveis, todas as pessoas, em geral, que têm a seu cargo grupos de crianças, têm atitudes compreensivelmente protectoras em relação a elas $[\ldots]^{\prime \prime}$. Entretanto, seguem esses autores afirmando, que:

Certos lugares e certos grupos de crianças são mais acessíveis do que outros. As escolas são mais acessíveis do que os internatos, os asilos para os sem-abrigo ou grupo de apoio para mães solteiras adolescentes. 0 desejo dos responsáveis por protegerem a privacidade dos que têm ao seu cuidado é compreensível e louvável, mas existem grupos de crianças acerca dos quais a sociedade pouco conhece, necessitando por isso de aprofundar esse conhecimento.

A essas circunstâncias (im)postas pelo campo juntam-se outras, apontadas pelos mesmos autores, e que dizem respeito a quem responde pelas crianças nesses contextos: o guardião de crianças. É com ele com quem primeiro tem-se que negociar e é de quem dependerá, de início, a autorização para a entrada no campo. Na maioria das vezes, trata-se de um profissional da administração que não tem contato direto com as crianças que se constituirão em sujeitos da pesquisa. Aqueles que têm contato diário com as crianças, os educadores sociais, por exemplo, esses raramente estão em posição de decidir por essa permissão para a entrada, muito embora, como salientam Graue e Walsh (2003), possam negar essa autorização, de maneira não oficial, isso é, não cooperando com o processo da pesquisa.

Tal como indicam esses autores, do mesmo modo, um longo período de negociações foi agenciado pelas pesquisas que realizamos nos dois contextos de acolhimento institucional, visando obter as autorizações necessárias para a entrada nesses campos. Foi preciso compreender que a natureza do trabalho desenvolvido 
nessas instituições constitui constantes tensionamentos, especialmente no que versa aos direitos de proteção da criança e ao sigilo técnico, ocasionando extensas burocracias institucionais. Inicialmente, toda a discussão em prol dessas autorizações foi mediada pelas guardiãs6, para quem foram apresentadas as pesquisas e pesquisadoras e, posteriormente, em reunião com as equipes técnicas de ambos os contextos7.

Quando do acesso ao campo, as educadoras sociais estavam cientes desta inserção, mas ainda assim, nas duas instituições foram realizadas, nas imersões seguintes, conversas com o propósito de esclarecer os objetivos e métodos da pesquisa, bem como os trâmites para autorização formal, fator que certamente contribuiu para a não confirmação do que Graue e Walsh (2003) argumentaram a respeito da não cooperação de tais profissionais nos processos de pesquisa. Também tivemos preocupação em deixar as crianças cientes da nossa presença, situação essa que trataremos mais adiante nesse texto.

Frente ao exposto, o que queremos reforçar é que este ponto de acesso ao campo exprime a necessidade de atender a protocolos instituídos pela legislação e que instauram um olhar sobre as formas de aproximação às crianças em contextos de vulnerabilidade social. Estes protocolos propõem uma negociação mediada pelos adultos, ainda que numa pesquisa cuja participação infantil seja o interesse central. Num primeiro olhar, é viável refletir: como, mais uma vez, os imperativos de risco surgem em detrimento à plena participação e tomada de decisão das crianças? Entretanto, por outra ótica possível, o questionamento pode se transmutar para: seria possível outro modo de gerir institucionalmente a questão do sigilo?

A partir desta dobradura de olhares, o que nos parece neste ponto é que não há uma forma de tratar tais pesquisas, sem pensa-las também considerando a iminente existência de protocolos legais, que nos movem a adequar a forma como nos inscrevemos nestes espaços, reconhecendo os direitos de proteção neles evidenciados. Sobre essa questão bastante complexa no que se refere às pesquisas com crianças, Ferreira (2010, p. 160) apresenta subsídios para ampliar a reflexão relacionada ao direito de proteção que é assegurado às crianças (em decorrência da pouca idade e de

6 No caso de abrigo público, o consentimento foi assinado pela diretora de proteção especial, vinculada à Secretaria Municipal de Desenvolvimento Social, acompanhada pela equipe técnica. Em se tratando do contexto privado, a assinatura ficou ao encargo da coordenadora da instituição, com anuência da presidência da entidade.

7 Equipes constituídas por psicólogas e assistentes sociais, ressaltando que no Abrigo privado a equipe também contava com uma pedagoga. 
ter um adulto responsável por ela) e o direito de participação em assuntos que Ihes dizem respeito, com vistas a "subscrever e ratificar os seus direitos como pessoa na pesquisa, à luz da Convenção dos Direitos das Crianças".

Na mesma direção, Soares (2005) aponta que a Convenção sobre os Direitos da Criança configura uma demarcação histórica para um novo modo de olhar para os direitos da criança, considerando sua individualidade, personalidade e diversidade, buscando reconhecer os direitos de provisão (direitos sociais de saúde, educação, segurança, etc.), proteção (contra discriminação, abusos, negligência, etc.) e participação (direitos civis e políticos, participar, ser ouvida, etc.). Afirma, entretanto, que há um consenso maior em relação às duas primeiras categorias, sendo que, o que versa sobre os direitos de participação há um constante tensionamento, tendo em vista o reconhecimento dos direitos civis básicos da infância e de poder participar ativamente de decisões que interferem diretamente em sua vida, porém também de uma perspectiva social que enxerga a criança como dependente do adulto e incapaz de agir sob tal responsabilidade.

Esta segunda perspectiva, corroborada por teorias clássicas do desenvolvimento encoraja a proteção das crianças e

[...] os limites da sua liberdade para a altura em que elas sejam capazes de perceber o alcance, abrangência e efeitos das suas acções. Essas perspectivas defendem que tais direitos requerem capacidades relacionadas com a razão, racionalidade e autonomia, que as crianças supostamente não possuem, sendo portanto desejável o adiamento do exercício dos mesmos, para o momento em que elas desenvolverem tais competências e atingirem assim o estatuto de pessoas (SOARES, 2005, p.16).

Um dos resultados destes embates de ordem ética acaba sendo a dificuldade em acessar os contextos de acolhimento institucional para a produção científica dos Estudos da Infância. Neste sentido, recorremos à Trindade e Rasera (2013) para fazer uma defesa da perspectiva ética enquanto um dado relacional. Embora na pesquisa acadêmica não possamos abandonar um discurso prescritivo que fundamenta um caráter contratual do fazer ético - tais como as exigências dos comitês, os cuidados com consentimento informado, e todos os demais procedimentos que visam salvaguardar os direitos das pessoas - os autores reconduzem uma compreensão da ética como algo que é criado e recriado nas negociações dentro das microrrelações. Em outras palavras, buscam compreender a ética não como um impasse definido previamente por condições externas, mas sim como uma construção linguística dialógica, pautada nos sentidos atribuídos pelos sujeitos envolvidos. 
Em um contexto como os agenciados pelas pesquisas aqui em relevo, que, especialmente por conta da sua especificidade, requer que percorramos por tantos protocolos legais, a facilitação do ingresso neste espaço se dará a partir de um trabalho crítico e eticamente posicionado. Esses vieses dialogam com a perspectiva da ética relacional, enquanto um dado construído a partir dos sentidos de sujeitos contextualmente localizados e em interação, ultrapassando a lógica instituída.

Mais uma vez, não podemos eliminar a necessidade de consentimento formal pelo adulto responsável pela criança, atendendo às exigências éticas postuladas na Resolução CNS 510/2016, que versa sobre as normas aplicáveis às pesquisas em Ciências Humanas e Sociais, cujas estratégias metodológicas envolvam os dados construídos diretamente com seres humanos. Contudo, a própria resolução institui indo ao encontro da literatura aqui assentada - o assentimento como a anuência dada pelos sujeitos em participar da pesquisa "na medida de sua compreensão e respeitadas suas singularidades, após esclarecimento sobre a natureza da pesquisa, justificativa, objetivos, métodos, potenciais benefícios e riscos" (BRASIL/CNS, 2016).

Neste sentido, ao mesmo tempo em que é problemática a adoção de termos rígidos de consentimento informado, onde talvez - mais uma vez - o adulto dite sobre como será a participação das crianças, também pode ser um equívoco do pesquisador contar que o consentimento dos adultos será suficiente, sem considerar o desejo ou a recusa da criança em participar e ser interlocutora da pesquisa. Assim, um claro obstáculo na pesquisa com crianças é o risco de "as infantilizar, considerando-as e tratando-as como imaturas e, ao fazê-lo, produzir provas para o reforço de noções da sua incompetência" (ALDERSON, 2005, p. 264).

No que diz respeitos às pesquisas aqui em destaque, em ambas a preocupação por ouvir as crianças, desde a entrada no campo, se constituiu em um "processo negociado" (FERREIRA, 2002, p. 150), iniciado com os adultos e, no decorrer de todo o percurso, efetivado a partir do encontro com as meninas e meninos que habitavam os contextos de acolhimento, sempre considerando "a importância de obter a permissão das crianças de um modo compreensivo e contextualizado ao longo da pesquisa", conforme indica Ferreira (2010, p. 153) e sobre o qual voltaremos a tratar na próxima seção.

A noção de assentimento aqui adotada compactua com a postulação de Ferreira (2010) que, parafraseando as autoras Alderson e Morrow (2004), indica que o assentimento provém da aceitação de que as crianças não têm idade legal para o consentimento formal e de que entendem algumas, porém não todas, as questões sobre 
as quais versam o consentimento e que, por fim, este assentimento pode ser impresso através de uma "não recusa" em participar da pesquisa. Assim, a compreensão desta aceitação ou não, requer dos pesquisadores e pesquisadoras um olhar sensível, disposto a analisar continuamente as dinâmicas relações que se estabelecem entre crianças e pesquisadores/as, sem deixar de refletir até que ponto o adulto é capaz de interpretar esta recusa ou aceitação, visto que

[...] não recusar, ou como diz o ditado popular, 'quem cala consente', não significa necessariamente aceitar, ou aceitar passivamente, do mesmo modo que afirmar verbalmente 'não' pode não ter o significado inequívoco de recusa efectiva pois muitos poderão ser os seus sentidos e esses só são, eventualmente, apreensíveis no contexto da relação e das circunstancias particulares em que ocorre (FERREIRA, 2010, p.164).

Por fim, é importante não perder de vista que a entrada em campo é sempre mediada, porque autorizada pelos adultos, no caso do acolhimento institucional, pelo guardião. Entretanto, a aceitação da pesquisa pelos adultos não significa, necessariamente, ser aceito pelas crianças. E, sem a aceitação dos sujeitos, não há pesquisa. As autoras Barbosa, Delgado e Tomás (2016, p. 113), indicam ainda que "nos Novos Estudos da Criança, a intenção é possibilitar o encontro com as crianças situadas contextualmente, escutá-las, traduzi-las e afirmá-las como um ato de liberdade".

É neste sentido que entendemos a etnografia como uma técnica investigativa calcada numa ciência do concreto, que tem como ponto de partida metodológico a interação entre o pesquisador e seus sujeitos de estudo, "com ênfase no cotidiano e no subjetivo" (FONSECA, 1998, p. 10). Assim, é exigido do pesquisador um cuidado éticoestético-afectivo para não cair na encruzilhada de considerar a etnografia meramente um conjunto de procedimentos antropológicos para a compreensão de uma realidade social alheia a sua própria. Trata-se de um caminho metodológico possível na pesquisa com crianças, por ser pautada pelo princípio da alteridade e do diálogo com via para a compreensão das diferenças culturais. Institui, portanto, uma premissa dialógica no reconhecimento das crianças como competentes interlocutoras, capazes de falar por si próprias e que operam sistemas simbólicos e agenciam relações entre os outros "com peculiaridades que se diferem do adulto não em qualidade, mas em lógica, no modo de pensar o mundo" (BRITO, 2014, p.42). 


\section{ATENDIDO AOS PRECEITOS LEGAIS: O ENCONTRO COM AS CRIANÇAS}

Depois de colocado em evidência o caminho trilhado para obtenção do consentimento informado, de modo a superar a ideia de um mero protocolo, mas entendendo-o a partir de uma expressiva mudança no entendimento sobre as crianças e sobre a relação adultos-investigadores e crianças, que passam a ser compreendidas não mais como objetos da investigação, mas como atores sociais que interpretam, decidem e intervém nos contornos assumidos na pesquisa (FERREIRA, 2010), reservamos essa seção para dizer dos modos em comum adotados por nós nas duas pesquisas, com vistas a aproximação às crianças, rumo a consolidação do assentimento por parte dos meninos e meninas sujeitos das pesquisas, trilhado não pelo caminho do silêncio e da exclusão, mas protegendo essas crianças de "investigações camufladas, invasivas, exploradoras ou abusivas" (ALDERSON, 2005, p. 263).

As contribuições de Manuela Ferreira (2010), ao descrever sobre sua primeira imersão em campo em uma investigação etnográfica com crianças em um jardim de infância português e tratar da complexidade e ambiguidade em interpretar o assentimento das crianças, aponta para a desconstrução de saberes absolutistas que historicamente acompanharam as pesquisas sobre a infância. Esse indicativo nos ajudou a perceber que o trânsito pela pesquisa educacional requer entender que não se agencia somente o acesso às novas teorias, epistemologias e métodos, mas em especial, demanda também um aprofundamento dos olhares lançados às crianças.

A exigência de uma sensibilidade ética para interpretar o que as crianças têm a dizer a respeito de sua participação ou não da pesquisa implica no esforço de redescobrir a atuação do pesquisador a partir do reconhecimento das assimetrias inerentes aos adultos e crianças, e das preocupações em manter contínua esta interpretação do assentimento, estabelecendo com as crianças relações por meio das quais elas ocupem o lugar de sujeitos que operam sobre a pesquisa (MÜLLER; CARVALHO, 2009). Essas autoras refletem que na pesquisa, adultos e crianças, inevitavelmente, estão em uma posição de diferença, entretanto, compreender e se colocar na diferença não é a mesma coisa que produzir uma relação de desigualdade na pesquisa, onde o adulto não leva em conta a agência das crianças e, considerando as diferentes ações e instrumentos que elas operam "é preciso estar atento às suas outras linguagens [...], tais como: o 
choro, o silêncio, o gestual, a agitação, a recusa, a transgressão, enfim, a sua diferença" (2010, p. 71).

No que concerne o processo de assentimento nas pesquisas aqui em diálogo, em se tratando do estudo de Nazário (2014), em virtude das idades das crianças (zero a seis anos), a opção feita foi por não as reunir e fazer uma conversa para apresentação da proposta, visto que deste modo apenas uma parcela delas seria contemplada, levando em conta que este arranjo restringiria o direito de participação direta dos bebês. Esta escolha está apoiada em Fine e Sandstrom (1988, apud FERREIRA, 2010, p. 162-163) quando defendem que se torna "difícil, se não impossível, discutir o estudo das crianças, abstraindo da análise das suas idades. Parece absurdo discutir técnicas, colocando na mesma rubrica idades entre os 2 e os 17 anos".

Tendo em conta as diferenças intrageracionais, a opção, então, foi a de entrar nos espaços em que as crianças se encontravam, sentar e esperar que elas percebessem a presença da pesquisadora, ou seja, a de adotar a estratégia da "entrada reativa", tal como expresso por Corsaro (2009). No entanto, o primeiro encontro já foi suficiente para dissipar tal desejo, conforme mostra o excerto de um dos registros retirado da pesquisa.

Chego à sala de estar (espaço assim nomeado pelas Orientações Técnicas para Serviços de Acolhimento e que sigo a indicação por assemelhar-se mais a perspectiva de uma residência) e encontro duas educadoras sentadas no sofá. Em um colchão no chão há um bebê recostado em almofadas e muito atento a TV que estava ligada em uma emissora de canal aberto [...]. Sento-me numa das pontas do colchão e parece que logo sou notada por ele, que sorri. Interpreto isso como um anúncio de boas-vindas e, então, me apresento a ele, sorrindo e Ihe dizendo "oi". A partir desse momento, passo a dividir a atenção entre as conversas com as educadoras e os sorrisos, toques e falas rápidas com o Gabriel, o bebê [...]. Neste misto de atenção distribuída às educadoras e ao Gabriel, surge outro menino, o João, uma criança maior. Olha-me e se dirige ao Gabriel, com quem começa a falar e que the responde atentamente, com sorrisos e muito resmungo. Passados uns minutos, João me olha e pergunta meu nome. Apresento-me e pergunto o seu nome. Ele responde prontamente e volta a conversar com o Gabriel. [...] Em seguida, começa a me contar sobre as crianças da casa, a falar dos bebês. [...] Gabriel estende a mão em minha direção, como se quisesse me dar o brinquedo ou convidarme para brincar. Aceito o convite e divido a conversa entre ele e Joãos (NAZÁRIO, 2014, p. 106-107).

Não muito diferente foi o que experienciou Tizatto (2018), no seu contato com as crianças, quando igualmente projetou ocupar uma "posição periférica" (AGOSTINHO,

8 Outras situações de aproximação das crianças se deram nesse primeiro dia. Entretanto, dado o contingenciamento de um artigo, optamos por apresentar apenas parte do registro. 
2010), a qual foi contestada por três diferentes vertentes, a pesar: i) a própria ânsia por buscar interação e aproximação com as crianças; ii) o reconhecimento da utopia inerente à noção de familiaridade; e iii) as discussões conduzidas em orientação e as múltiplas leituras indicadas que corroboram com esta consciência sobre a fragilidade de uma entrada reativa.

Na primeira imersão no campo, as crianças já demonstraram seu interesse ou curiosidade a meu respeito. Destaco um destes momentos em que a minha presença naturalmente evocou questionamentos, que foi quando conheci duas meninas, de cinco e nove anos, as quais encontrei pela primeira vez no refeitório, onde eu estava sentada aguardando as crianças voltarem de uma atividade de contraturno escolar. As duas meninas chegaram juntas, perguntaram para a coordenadora quem eu era - até aí, as meninas me enxergavam, mas ao pedir para que outros falassem sobre mim, ainda me mantinham às margens; distante. Após a explicação, sentaram do meu lado e me perguntaram se eu poderia dormir no quarto das meninas após o almoço e, mais tarde no mesmo dia, quando eu iria voltar para brincar de novo, abrindo para mim um espaço não-tão-às-margens, que não se satisfaz com as periferias das relações (TIZATTO, 2018, p. 88).

Para além dos impactos da entrada no campo, os quais colocaram algumas das nossas premissas em suspensão, o que queremos demarcar a partir desses excertos é a forma como as crianças foram nos autorizando a ocupar nosso lugar de pesquisadoras naqueles contextos. Uma autorização gradual, traduzida pelo sorriso de uma bebê, por uma conversa sobre as crianças da casa ou, ainda, por um convite para dormir depois do almoço ou brincar. Ou seja, formas de consentir que se configuraram a partir dos "usos sociais que as crianças fazem da pesquisadora (FERREIRA, 2002, p. 160).

Nesse sentido, a corrente interpretativa assumida por essas pesquisas contribuiu para compreender que a criança reproduz a cultura societal por meio da relação com adultos, a recria, (re)significa e a exprime atravessada por subjetividade na relação entre pares, despontando para o interesse pelo estudo das relações intra e intergeracionais e das culturas infantis (SARMENTO, 2009). Também nos possibilitou entender que "toda interpretação, em virtude de focalizar as vidas das pessoas, é um ato ético" (MONTEIRO, 1998, p. 17).

Esse percurso exigiu a construção de uma ética viável que fosse capaz de construir relações horizontalizadas em pesquisa com as crianças e acautelar sobre a escrita acadêmica, de modo a não agir como detentor das vozes das crianças, manipulando-as conforme o próprio contexto do pesquisador, suas intenções institucionais e interpretações, privando-as de autoria (FERNANDES, 2016). 
As relações horizontalizadas na pesquisa com crianças se assenta na ideia de que elas - as crianças - devem ser ouvidas, consultadas, informadas, envolvidas e legitimadas, não vistas meramente como objeto de interesse dos adultos, mas reconhecidas como sujeitos de direitos, sujeitos de suas próprias vidas. Isso exige do pesquisador a conduta de constantemente se questionar sobre ouvir a criança, de modo a escutar o que ela tem a dizer, e não o que os adultos querem que ela diga. Para tanto, é preciso estar atento, disposto e disponível para conversar e para ouvir palavras e silêncios, e mais do que isso, estar também preparado e qualificado para essa escuta (ROSSETTI-FERREIRA; SERRANO; ALMEIDA, 2011).

A busca pela desconstrução de um padrão de pesquisa em que perpetue uma lógica de detenção do saber na figura do adulto se deu a partir do momento em que nos propusemos a entender o conhecimento das crianças sobre suas vidas e, principalmente, reconhecer que este conhecimento só pode emanar diretamente da experiência das crianças. Isso exigiu assumir uma ética de complexidade.

Outro aspecto está relacionado a cautela na geração de dados e na escrita acadêmica, de modo a não apenas ouvir o que a criança tem a nos dizer, mas agir adequada e eticamente sobre esse conhecimento infantil, buscando não transformar os anúncios das crianças em repostas que testam e respondem às nossas hipóteses adultas. Ouvir e conversar com as crianças, escovar suas palavras,, escavar os diálogos, explorar seus conhecimentos e o posicionamento social discutindo sobre o que dizem. Ou seja, ter, de fato, a conversa como método de construção de dados de pesquisa, a partir de diálogos nos quais a criança possa conduzir o rumo do que será dito, buscando fugir de perguntas tendenciosas que os métodos participativos podem usar como disparadores de recolha de dados (MAYALL, 2005).

Christensen e James (2005) defendem que o diálogo contínuo é importante para que tanto as crianças quanto os adultos investigadores se sintam no controle dos contornos tomados pela pesquisa, e que as crianças tenham a experiência de que seus pontos de vista não sejam negligenciados pelos adultos. O longo tempo de permanência no campo, a familiaridade estabelecida entre as crianças e pesquisadoras, a observação participante, o diálogo, o registro detalhado e a análise sistemática de todas essas informações, figuram aqui como os desafios assumidos para reconhecer a agência 10 das

9 Parafraseando Manoel de Barros (2003).

10 A expressão agência, para a Sociologia da Infância, está relacionada "às maneiras que as crianças encontram para se organizar e agir autonomamente em seus grupos (com seus pares), bem como as relações que estabelecem com outros grupos sociais" (SANTOS, 2012, p.236). Em outras palavras, é reconhecer e observar as crianças em suas ações e relações com o mundo, 
crianças, tanto no processo de pesquisa, quanto no anúncio das práticas políticas e institucionais, evidenciando como as crianças vivem a suas experiências dentro do Abrigo.

Assumindo a todos esses desafios, a questão de interpretação do assentimento das crianças constituiu em um exercício colocado em prática ao longo de todo o percurso de ambas as pesquisas aqui tratadas, frente a característica implícita de provisoriedade e transitoriedade deste campo marcado por chegadas e partidas de crianças, incidindo diretamente sobre as formas de registrar toda a dinâmica que compõe os contextos de acolhimento institucional. Envolvidas neste processo, como pesquisadoras, aprendemos a tomar o Abrigo como um lugar de oportunidades para o encontro com o desconhecido, de contiguidade com o estranho e de contato com outras múltiplas experiências de vida.

Neste espiral de heterogeneidades, o movimento de circulação pelos diferentes espaços dos Abrigos e em diferentes horários do dia e da noite11 nos possibilitou formas variadas e singulares de comunicação. Imersas nestes universos, acolhemos estas comunicações e, através dos registros escritos, fílmicos e fotográficos, capturamos as narrativas das crianças, no sentido dar visibilidade à multiplicidade de infâncias daquele/naquele lugar. $E$, pelas narrativas das crianças seguimos entresonhadas a acreditar na importância de continuar escovando palavras sobre as experiências das crianças nos programas de acolhimento institucional, sem jamais pensar em jogar a escova fora12.

\section{CONSIDERAÇÕES FINAIS}

Quem vive num labirinto, tem fome de caminhos.

(Mia COUTO)

ao invés de compreendê-las como miniaturas adultas, que reeditam a vida dos adultos (BRITO, 2014). Neste caminho, assumir a agência das crianças se configura também como um desafio para a Sociologia da Infância, num movimento de libertá-la do pensamento moderno que estabelece a dicotomia entre agência (reconhecimento das crianças como atores sociais e de infâncias constituídas localmente e diversamente a partir da interação entre múltiplos atores) e estrutura (com a padronização em larga escala das características da infância de determinada sociedade) (PROUT, 2010).

11 Vale registrar que as estratégias para a permanência no Abrigo, em ambas as pesquisas, variaram. Frequentamos tais espaços em período diurno nos dias uteis e também nos finais de semana, ocupamos períodos noturnos, habitamos os Abrigos por períodos mais prolongados (chegando, num dos casos, a passar, por várias vezes, toda a semana com as crianças e adultos da instituição, se constituindo quase que em uma moradora da casa).

12 Novamente compondo com Manoel de Barros (2003). 
A definição metodológica das pesquisas que originaram este texto se deu a partir da construção de um olhar interdisciplinar sobre a infância, oriunda das constantes leituras e discussões ligadas aos Estudos da Infância e, nesse sentido, nosso esforço se pautou na necessidade de reconhecer as diferenças entre adultos e crianças e trabalhar em prol de não converter tal diferença em uma relação de poder ou uma relação de desigualdade que, seguindo uma marca de exclusão historicamente sobreposta à infância, marginaliza os discursos e saberes infantis.

Ao longo da escrita buscamos dar visibilidade aos percursos e percalços vividos quando o assunto versa sobre a aproximação dos pesquisadores adultos aos sujeitos de pouca idade que habitam os Abrigos e Casas Lares, e que, por vezes, ainda aparecem como (in)visíveis e (des)conhecidos, mesmo diante da ampliação de pesquisas em torno dessa temática, se levarmos em conta que, em muitos casos, essas pesquisas são forjadas sobre os saberes adultos e, sob essa condição, falam em nome dessas crianças ou por elas.

Tentamos lançar luz sobre os processos teórico-metodológicos adotados pelas duas pesquisas que realizamos em Abrigos catarinenses, intencionadas a refletir dois pontos que se interseccionam: i) as implicações postas para a entrada no campo, sob a forte tensão entre o direito de proteção e o direito de participação das crianças; ii) a emergência por desenvolver estratégias comunicativas que envolvam as crianças nas pesquisas, construídas sobre as próprias habilidades e capacidades dessas crianças.

No que se refere ao primeiro ponto, entendemos que cabe uma profunda reflexão em relação aos trâmites éticos da pesquisa ao considerar a importância dos processos para acesso às crianças, como a necessidade de consentimento formal pelo adulto, especialmente em contextos marcados por condições de vulnerabilidade e violências, evitando desconsiderar a exigência de se preservar os direitos de proteção das crianças. Contudo, é preciso considerar que é problemático resumir os esforços éticos da pesquisa às exigências regulamentadoras, ato que reforça, de certo modo, as noções de imaturidade e incompetência infantil (ALDERSON, 2005) que tanto marcam a história da assistência à infância brasileira.

Essa questão nos impele a pensar o segundo aspecto apontado, visto que o exercício ético-estético-afectivo de se fazer pesquisa com crianças em contexto de acolhimento institucional convoca uma interpretação sensível e contínua do assentimento que as próprias nos transmitem em relação a participar ou não na pesquisa, considerando sua capacidade e competência de interlocutoras que falam por si próprias. 
O entendimento de que o direito ao consentimento tem impacto em todos os demais direitos das crianças, e de que a capacidade de elas poderem, por si próprias, dar o seu consentimento, depende, em larga escala, da possibilidade que têm em falar e de se fazerem ouvidas no decorrer de todo o processo da pesquisa. Assim, importa pensar que a participação infantil precisa ser tomada como aspecto central para a definição de um estatuto social da infância, sendo indispensável a agência das crianças, sua voz, seu ponto de vista. Ou seja, emerge a necessidade de lançar um olhar descomparado (BARROS, 2003) e criar condições para a "inteligibilidade recíproca" entre os mundos das crianças e dos adultos, inteligibilidade esta assentada em "metodologias próximas da tradução", que permitam detectar as zonas de contato entre estas duas categorias geracionais, sem que isso represente a perda de identidade e de autonomia de nenhum deles (SANTOS, 2003).

Entendemos que fazer isso implica tensionar sobre o desafio do exercício ético de pesquisar com crianças, na linha tênue que separa e aproxima os direitos de proteção e os de participação. Volver o olhar para as crianças nos meandros das políticas de proteção integral à infância é um ato de assinalar o deslocamento previsto na legislação brasileira, no qual as crianças ultrapassam a concepção de objeto da proteção rumo ao lugar de cidadão, problematizando, neste interim, os múltiplos planos de existências que constroem diferentes discursos e ações neste espaço e as incongruências entre a agência das crianças e as formas como os adultos agem em relação a elas (BRITO, 2014).

Por fim, importa destacar que os limites e desafios da pesquisa acadêmica, apontados ao longo desse artigo, não podem ser enxergados unicamente com o olhar da crítica, pois embora esbarremos em determinados entraves para o reconhecimento da autoria e da participação das crianças - em muito justificados pela legítima necessidade de respeitar seus direitos de proteção - evidenciar as narrativas infantis é também amplificar na academia e na prática profissional a importância de se ouvir as crianças, considerando-as como sujeitos com agência, capazes de construir ativamente suas próprias histórias. Assim, neste labirinto que implica as pesquisas com crianças, em especial, com aquelas que não tem seu direito ao convívio familiar e comunitário assegurado e que, por isso, estão sob a tutela de outros responsáveis, seguimos 
famintas por novos caminhos que nos ajudem a superar alguns dos desafios apontados neste texto, sem deixar de considerar que o caminho faz-se ao caminhar13.

\section{REFERÊNCIAS}

ALDERSON, Priscilla; MORROW, Virgínia. Ethics, social research and consulting with children and young people. Barkingside: Barnardo's, 2004.

ALDERSON, Priscilla. Crianças como investigadoras: os efeitos dos direitos de participação na metodologia de investigação. In: Pia Christensen e Allison James (orgs.). Investigação com crianças: perspectivas e práticas. Escola de Educação Superior de Paula Franssinetti. Porto: Ediliber Editora de Publicações Ida, 2005.

BARBOSA, Maria Carmen Silveira; DELGADO, Ana Cristina Coll; TOMÁS, Catarina Almeida. Estudos da Infância, Estudos da Criança: Quais campos? Quais teorias? Quais questões? Quais métodos? Inter-ação, v.41, n.1. Goiânia: 2016.

BARROS, Manoel de. Memórias Inventadas: a infância. São Paulo: Planeta, 2003. BARROS, Manoel de. Memórias inventadas: a segunda infância. São Paulo (SP): Planeta, 2006.

BRASIL/CONSELHO NACIONAL DE SAÚDE. Resolução no 510, de 07 de abril de 2016. Quinquagésima nona reunião extraordinária CNS: 2016.

BRITO, Mirella Alves de. Entre cobras e lagartixas: crianças em instituições de acolhimento se construindo sujeitos na maquinaria da proteção integral. Tese de Doutorado em Antropologia Social. Programa de Pós-Graduação em Antropologia Social, Universidade Federal de Santa Catarina. Florianópolis: 2014.

BUCKINGHAM, David. Crescer na Era das Mídias Eletrônicas. São Paulo: Loyola, 2007.

CADERNOS DE PESQUISAS. São Paulo, no 31, dez. 1979.

CHRISTENSEN, Pia; JAMES, Allison. Introdução. Pesquisando as crianças e a infâncias: Culturas de comunicação. In: JAMES, Allison. (org.). Investigação com crianças: Perspectivas e práticas. Porto: Escola Superior de Educação Paula Frassinetti, 2005, p. XII-XX.

COUTO, Mia. E se Obama fosse americano? São Paulo: Cia das Letras, 2009.

DELGADO, Ana Cristina Coll; MÜLLER, Fernanda. Abordagens etnográficas nas pesquisas com crianças. In: CRUZ, Silvia Helena Vieira. (Org.) A criança fala: a escuta de crianças em pesquisas. São Paulo: Cortez, 2008.

13 Livre tradução de parte da poesia do espanhol Antônio Machado, intitulada Proverbios y cantares, publicada no livro Campos de Castilla. "Al andar se hace el caminho" 
FERNANDES, Natalia. Ética na pesquisa com crianças: ausências e desafios. In: Revista Brasileira de Educação. v.21. n.66: jul-set, 2016.

FERREIRA, Maria Manuela. Os estranhos sabores da perplexidade numa etnografia com crianças em jardim de infância. In: CARIA, Telmo. Experiência etnográfica em Ciências Sociais. Porto: Afrontamentos, 2002, p. 149-166.

FERREIRA, Maria Manuela. "Ela é nossa prisioneira!" - questões teóricas, epistemológicas e ético-metodológicas a propósito dos processos de obtenção da permissão das crianças pequenas numa pesquisa etnográfica. Revista Reflexão e Ação. Santa Cruz do Sul, v. 18, n. 2: 2010.

FONSECA, Claudia. Quando cada caso NÃO é um caso: pesquisa etnográfica em educação. In: Anais da XXI Reunião Anual da ANPEd. Caxambu-MG, setembro de 1998.

GEERTZ, Clifford. O saber local. 8. ed. Petrópolis: Vozes, 1999.

GRAUE, Elizabeth; WALSH, Daniel. Investigação etnográfica com crianças: teorias, métodos e ética. Lisboa: Fundação Calouste Gulbenkian, 2003.

GUSMÃO, Neusa Maria Mendes de. Antropologia e Educação: origens de um diálogo. In: GUSMÃO, Neusa Maria Mendes de. (Org.). Antropologia e Educação: interfaces do ensino e da pesquisa. Cadernos Cedes, Cedes/Unicamp, no 43, ano XVIII. p. 8-25, dezembro de 1997.

IBGE, Diretoria de Pesquisas, Coordenação de População e Indicadores Sociais. Estimativas da população residente com data de referência $1^{\circ}$ de julho de 2017. Disponível em: https://cidades.ibge.gov.br Acesso em 12 dezembro 2018.

KRAMER, Sonia. Formação e Responsabilidade: escutando Mikhail Bakhtin e Martin Buber. In: KRAMER, Sonia; NUNES, Maria Fernanda; CARVALGO, Maria Cristina, (orgs.). Educação infantil: Formação e responsabilidade. $1^{\mathrm{a}}$ ed. Campinas, SP: Papirus, 2013.

KUHLMANN JUNIOR, Moysés. Infância e Educação Infantil. $2^{a}$ Ed. Porto Alegre: Mediação, 1998.

MAGNANI, José Guilherme Cantor. De perto e de dentro: notas para uma etnografia urbana. In: Revista Brasileira de Ciências Sociais, vol. 17, n. 49, fevereiro, 2002.

MAYALL, Berry. Conversa com crianças: trabalhando com problemas geracionais. In: CHRISTENSEN, Pia; JAMES, Allison. (orgs.). Investigação com crianças:

perspectivas e práticas. Escola de Educação Superior de Paula Franssinetti. Porto: Ediliber Editora de Publicações Ida., 2005.

MONTEIRO, Roberto Alves. Pesquisa em Educação: Alguns desafios da abordagem qualitativa. In: MONTEIRO, Roberto Alves. Fazendo e Aprendendo Pesquisa Qualitativa em Educação. Juiz de Fora: FEME/UFJM, 1998.

MUller, Fernanda; CARVAlho, Ana Maria Almeida. Teoria e Prática na Pesquisa 
com Crianças: diálogos com Willian Corsaro. São Paulo: Cortez, 2009.

O'KANE, Claire. O desenvolvimento de técnicas participativas: facilitando os pontos de vista das crianças acerca de decisões que as afectam. In: CHRISTENSEN, Pia; JAMES, Alison. (org.). Investigação com crianças: Perspectivas e práticas. Porto: Escola Superior de Educação Paula Frassinetti, 2005.

PINTO, Manuel; SARMENTO, Manuel Jacinto. As crianças: contextos e identidades. Braga/ Portugal: Ed. Bezerra, 1997.

PROUT, Alan. Participação, política e as condições da infância em mudança. In: MULLER, Fernanda. (org.). Infância em perspectiva: políticas, pesquisas e instituições. São Paulo: Cortez, 2010.

ROCHA, Eloisa Acires Candal. Diretrizes Educacionais: Pedagógicas para a Educação Infantil. In: Prefeitura Municipal de Florianópolis. Secretaria Municipal de Educação. Diretrizes Educacionais Pedagógicas para Educação Infantil. Florianópolis: Prelo Gráfica \& Editora Itda, 2010, p. 11-21.

ROSSETTI-FERREIRA, Maria Clotilde; SERRANO, Solange Aparecida; ALMEIDA, IVy Gonçalves de. A criança e o adolescente como sujeito ativo e de direitos no processo de acolhimento institucional: uma longa história ainda inacabada. In: ROSSETTIFERREIRA, Maria Clotilde; SERRANO, Solange Aparecida; ALMEIDA, Ivy Gonçalves de. (orgs.). $O$ acolhimento institucional na perspectiva da criança. São Paulo: Hucitec, 2011.

SANTOS, Boaventura de Sousa. O Fórum Social Mundial. 2003. Disponível em: http://www.boaventuradesousasantos.pt/documentos/fsm.pdf Acesso em dezembro de 2018.

SANTOS, Maria Walburga dos. Crianças no tempo presente: a Sociologia da Infância no Brasil. In: Pro-Posições, v. 23, n. 2 (68), Campinas: maio/ago. 2012.

SARMENTO, Manuel Jacinto. Imaginário e culturas da infância. In: Cadernos de Educação Universidade Federal de Pelotas. Ano 12, no 21, jul/dez. Pelotas: FaE/UFPel, 2003. p. 51-70.

SARMENTO, Manuel Jacinto. Crianças: educação, culturas e cidadania activa. In: Perspectiva, Florianópolis, v.23, n.01.p.17-39, jan./jun. 2005.

SARMENTO, Manuel Jacinto. Sociologia da Infância: correntes e confluências. In: SARMENTO, Manuel Jacinto; GOUVEA, Maria Cristina Soares de. (orgs.). Estudos da Infância: educação e práticas sociais. 2. ed. Petrópolis, RJ: Vozes, 2009.

SARMENTO, Manuel Jacinto. A Sociologia da Infância e a sociedade contemporânea: desafios conceituais e praxeológicos. In: ENS, Romilda Teodora; GARANHANI, Marynelma Camargo. (Orgs.). Sociologia da Infância e a formação de professores. Curitiba-PR: Champagnat - Editora PUC PR, 2013.

SILVA, Juliana Pereira da; BARBOSA, Silvia Neli Falcão; KRAMER, Sônia. Questões teórico-metodológicas da pesquisa com criança. In: Perspectiva. Florianópolis: CED/UFSC, 2005. 
SOARES, Natalia Fernandes. Os direitos das crianças nas encruzilhadas da proteção e da participação. In: Zero-a-Seis, v.7. n.12, 2005.

TRINDADE, Flavia Miranda Oliveira, RASERA, Emerson Fernando. Considerações sobre uma ética relacional. In: Revista Psico, v. 44. n. 1. Jan/mar: 2013.

\title{
NOTAS
}

\section{PERCURSOS E PERCALÇOS DAS PESQUISAS COM CRIANÇAS EM CONTEXTOS DE CHEGADAS E PARTIDAS: REFLEXÕES SOBRE PESQUISAS EM PROGRAMAS DE ACOLHIMENTO INSTITUCIONAL}

\author{
Roseli Nazário \\ Doutora em Educação \\ Instituto Federal Catarinense - PPGE IFC, Campus Camboriú, Brasil. \\ Roseli.nazario@ifc.edu.br \\ (1) https://orcid.org/0000-0002-1825-0097 \\ Kamila Barros Tizatto \\ Mestra em Educação \\ Instituto de Ensino Superior Santo Antônio, Graduação em Pedagogia, Joinville, Brasil \\ kamila_tizatto@santoantonio.edu.br \\ Chttps://orcid.org/0000-0002-1825-0097
}

Endereço de correspondência do principal autor

Rua Gentil Sandin, 380 - Condomínio Villa das Flores / Bloco Alecrim - Apto 405.

Bairro Praia Comprida - CEP 88.103-650 - São José/SC

\section{AGRADECIMENTOS}

$-$

\section{CONTRIBUIÇÃO DE AUTORIA}

Concepção e elaboração do manuscrito: Todos os autores contribuíram substancialmente.

Coleta de dados: Todos os autores contribuíram substancialmente

Análise de dados: Todos os autores contribuíram substancialmente

Discussão dos resultados: Todos os autores contribuíram substancialmente

Revisão e aprovação: Todos os autores contribuíram substancialmente

\section{CONJUNTO DE DADOS DE PESQUISA}

O conjunto de dados que dá suporte aos resultados deste estudo não está disponível publicamente.

\section{FINANCIAMENTO}

Coordenação de Aperfeiçoamento de Pessoal de Nível Superior - CAPES DS

Programa de Bolsas Universitárias de Santa Catarina - UNIEDU

\section{CONSENTIMENTO DE USO DE IMAGEM}

Não se aplica.

\section{APROVAÇÃO DE COMITÊ DE ÉTICA EM PESQUISA}

Ambas as pesquisas foram aprovadas no Comitê de Ética UFSC.

Parecer 2.635.359 - Florianópolis-SC, 04 de maio de 2018.

\section{CONFLITO DE INTERESSES}

Não se aplica. 
LICENÇA DE USO - uso exclusivo da revista

Os autores cedem à Zero-a-Seis os direitos exclusivos de primeira publicação, com o trabalho simultaneamente licenciado sob a Licença Creative Commons Attribution (CC BY) 4.0 International. Esta licença permite que terceiros remixem, adaptem e criem a partir do trabalho publicado, atribuindo o devido crédito de autoria e publicação inicial neste periódico. Os autores têm autorização para assumir contratos adicionais separadamente, para distribuição não exclusiva da versão do trabalho publicada neste periódico (ex.: publicar em repositório institucional, em site pessoal, publicar uma tradução, ou como capítulo de livro), com reconhecimento de autoria e publicação inicial neste periódico.

PUBLISHER - uso exclusivo da revista

Universidade Federal de Santa Catarina. Núcleo de Estudos e Pesquisas da Educação na Pequena Infância - NUPEIN/CED/UFSC. Publicação no Portal de Periódicos UFSC. As ideias expressadas neste artigo são de responsabilidade de seus autores, não representando, necessariamente, a opinião dos editores ou da universidade.

EDITORES - uso exclusivo da revista

Márcia Buss-Simão e Kátia Agostinho.

HISTÓRICO - uso exclusivo da revista

Recebido em: 08-04-2019 - Aprovado em: 28-07-2019 